\title{
Protein Tyrosine Phosphatase $\alpha$ in the Dorsomedial Striatum Promotes Excessive Ethanol-Drinking Behaviors
}

\author{
Sami Ben Hamida, ${ }^{\star}$ Emmanuel Darcq, ${ }^{*}$ Jun Wang, ${ }^{\star}$ Su Wu, Khanhky Phamluong, Viktor Kharazia, and Dorit Ron \\ Gallo Center at the Department of Neurology, University of California, San Francisco, San Francisco, California 94143
}

We previously found that excessive ethanol drinking activates Fyn in the dorsomedial striatum (DMS) (Wang et al., 2010; Gibb et al., 2011). Ethanol-mediated Fyn activation in the DMS leads to the phosphorylation of the GluN2B subunit of the NMDA receptor, to the enhancement of the channel's activity, and to the development and/or maintenance of ethanol drinking behaviors (Wang et al., 2007, 2010). Protein tyrosine phosphatase $\alpha(\operatorname{PTP} \alpha$ ) is essential for Fyn kinase activation (Bhandari et al., 1998), and we showed that ethanolmediated Fyn activation is facilitated by the recruitment of PTP $\alpha$ to synaptic membranes, the compartment where Fyn resides (Gibb et al., 2011). Here we tested the hypothesis that PTP $\alpha$ in the DMS is part of the Fyn/GluN2B pathway and is thus a major contributor to the neuroadaptations underlying excessive ethanol intake behaviors. We found that RNA interference (RNAi)-mediated PTP $\alpha$ knockdown in the DMS reduces excessive ethanol intake and preference in rodents. Importantly, no alterations in water, saccharine/sucrose, or quinine intake were observed. Furthermore, downregulation of PTP $\alpha$ in the DMS of mice significantly reduces ethanol-mediated Fyn activation, GluN2B phosphorylation, and ethanol withdrawal-induced long-term facilitation of NMDAR activity without altering the intrinsic features of DMS neurons. Together, these results position PTP $\alpha$ upstream of Fyn within the DMS and demonstrate the important contribution of the phosphatase to the maladaptive synaptic changes that lead to excessive ethanol intake.

\section{Introduction}

Protein tyrosine phosphatase $\alpha(\mathrm{PTP} \alpha)$ is a transmembrane phosphatase that belongs to a superfamily of receptor-like protein tyrosine phosphatases (Tonks, 2006; Hendriks et al., 2013). PTP $\alpha$ is widely expressed in the brain (Sap et al., 1990; Sahin et al., 1995) and contributes to several functions in the developing and adult brain, including synaptic plasticity and learning and memory (Petrone et al., 2003; Skelton et al., 2003). Recently, a loss-of-function polymorphism within the PTP $\alpha$ gene has been reported to be associated with schizophrenia (Takahashi et al., 2011).

The most well-characterized substrates for PTP $\alpha$ are the Src family nonreceptor protein tyrosine kinases (PTKs) (Ohnishi et al., 2011), and numerous studies suggest a specific role for PTP $\alpha$ in the regulation of Fyn activity. PTP $\alpha$ directly interacts with Fyn and dephosphorylates the kinase on the inhibitory phosphotyrosine site (pTyr 527), leading to its activation (Bhandari et al.,

\footnotetext{
Received May 9, 2013; revised July 11, 2013; accepted July 26, 2013.

Author contributions: S.B.H., J.W., and D.R. designed research; S.B.H., E.D., J.W., S.W., K.P., and V.K. performed research; S.B.H., E.D., J.W., and D.R. analyzed data; S.B.H., E.D., J.W., and D.R. wrote the paper.

This work was supported by National Institutes of Health/National Institute on Alcohol Abuse and Alcoholism Grants R01AA 013438 and P50 AA017072 to D.R. and funds provided by the State of California for medical research on alcohol and substance abuse through the University of California, San Francisco (D.R.). We thank Dr. Stuart Gibb, Quinn V. Yowell, and Wenheng Zhu for technical assistance, and Dr. Somayeh Ahmadiantehrani for careful review of the manuscript.

The authors declare no competing financial interests.

*S.B.H., E.D., and J.W. contributed equally to this work.

Correspondence should be addressed to Dr. Dorit Ron, 675 Nelson Rising Lane, Box 0663, San Francisco, CA 94143-0663. E-mail:dron@gallo.ucsf.edu.

S. Ben Hamida's present address: Departement de Medecine Translationnelle et Neurogenetique, Institut de Biologie Moleculaire et Cellulaire, 1 rue Laurent Fries, 67404 Illkirch Cedex, France.

DOI:10.1523/JNEUROSCI.1954-13.2013

Copyright $\odot 2013$ the authors $\quad 0270-6474 / 13 / 3314369-10 \$ 15.00 / 0$
}

1998; Ponniah et al., 1999; Su et al., 1999; Zheng et al., 2000; Vacaresse et al., 2008; Vacaru and den Hertog, 2010). PTP $\alpha$ modulation of Fyn activity is necessary for NCAM-mediated neurite outgrowth (Bodrikov et al., 2005) and neuronal migration (Ye et al., 2008, 2011). One of Fyn's substrates is the GluN2B (Salter and Kalia, 2004; Ohnishi et al., 2011), and both Fyn (Yaka et al., 2002) and PTP $\alpha$ (Lei et al., 2002) are part of the NMDAR complex. By enabling Fyn to phosphorylate the GluN2B, the phosphatase positively regulates NMDAR activity, as well as long-term potentiation and learning and memory (Lei et al., 2002; Petrone et al., 2003; Skelton et al., 2003; Le et al., 2006).

We previously found that repeated systemic administration of ethanol, as well as repeated cycles of excessive ethanol intake and withdrawal, activates Fyn in the dorsomedial striatum (DMS) (Wang et al., 2010; Gibb et al., 2011), leading to the phosphorylation of GluN2B and to a consequent increase in synaptic membranal localization of GluN2B in the DMS (Wang et al., 2010, 2011). Importantly, we found that Fyn-mediated phosphorylation of GluN2B in the DMS plays a crucial role in the neuroadaptations that underlie ethanol-drinking and ethanol-seeking behaviors (Wang et al., 2010). More recently, we showed that repeated systemic administration of ethanol and binge ethanol intake promote the localization of PTP $\alpha$ to the synaptic fraction, where Fyn is localized (Gibb et al., 2011). We further observed that the movement of PTP $\alpha$ was specific to the DMS and was not observed in the dorsolateral striatum (DLS) or the nucleus accumbens (NAc) (Gibb et al., 2011). Here, we set out to test the hypothesis that PTP $\alpha$ in the DMS plays an important role in ethanol-mediated Fyn-dependent mechanisms, e.g., Fyn activation, GluN2B phosphorylation, the enhancement of channel activity, the molecular events underlying the development and/or maintenance of ethanol-drinking behavior. 


\section{Materials and Methods \\ Materials}

Mouse anti-NeuN and rabbit anti-PTP $\alpha$ antibodies were purchased from EMD Millipore. Rabbit anti-GAPDH, goat anti-GluN2B, goat anti-actin, and rabbit anti-Fyn antibodies were purchased from Santa Cruz Biotechnology. Rabbit anti-[pY1472] GluN2B and rabbit anti-[pY418/420] Src/Fyn antibodies were purchased from Cell Signaling Technology. Mouse antiGFAP antibodies and picrotoxin were purchased from Sigma. Rabbit antigreen fluorescent protein (GFP) antibodies were purchased from Abcam. Enhanced chemiluminescence (ECL) plus was purchased from GE Healthcare, and BioMax MR Film was purchased from Kodak. The p24 antigen ELISA kit was purchased from ZeptoMetrix. The inhibitors, NBQX and Ro 25-6981, were purchased from Tocris Bioscience. NuPAGE 10\% Bis-Tris gels, AlexaFluor-488-labeled donkey anti-rabbit, and AlexaFluor-594-labeled donkey anti-mouse were purchased from Invitrogen. Vectashield mounting medium was purchased from Vector Laboratories. Complete mini, EDTA-free protease inhibitor mixture was purchased from Roche. The Paris Kit was purchased from Ambion. The reverse transcription system and $2 \times$ PCR Master Mix were purchased from Promega.

\section{Animals}

Male Long-Evans rats (Harlan; 300-320 g, 3 months old) and male C57BL/6J mice (The Jackson Laboratory; 22-25 g, 3 months old) were individually housed in a temperature- and humidity-controlled room under a $12 \mathrm{~h}$ light/dark cycle, with food and water available ad libitum. All animal procedures in this report were approved by the Gallo Center Institutional Animal Care and Use Committee and were conducted in agreement with the Guide for the Care and Use of Laboratory Animals, National Research Council, 1996.

\section{Drugs and treatments}

Ethanol solution for the drinking experiments was prepared from absolute anhydrous ethanol (190 proof) diluted to $20 \%$ ethanol (v/v) in tap water. For systemic administration, ethanol was diluted to $20 \%$ ethanol (v/v) in saline.

\section{Collection of brain samples for molecular analyses}

Rats and mice were killed 4-7 weeks after virus infusion, respectively. Brains were quickly removed and placed on an ice-cold platform. Striatal tissues from individual rats or mice were collected and immediately homogenized in $300 \mu \mathrm{l}$ of either the Paris Kit cell-disruption buffer, for analysis of mRNA and protein knockdown, or radioimmunoprecipitation assay (RIPA) buffer as follows (in mu): 50 Tris- $\mathrm{HCl}, \mathrm{pH} 7.6,150 \mathrm{NaCl}, 2 \mathrm{EDTA}$, and 1\% NP-40, $0.1 \%$ SDS, and $0.5 \%$ sodium deoxycholate). Protease and phosphatase inhibitor cocktails were added to the lysate.

\section{Production of lentivirus-expressing shRNA targeting PTP $\alpha$}

The shRNA sequence targeting PTP $\alpha$ mRNA (5'-GCTGGGAGCCATTC CAATTC-3') was described previously (Zheng et al., 2008). The plasmid pLVX-shPTP $\alpha$ or pLVX-expressing nonspecific sequence (pLVX-shNS) (Jeanblanc et al., 2009) was transfected into HEK293FT cells along with the packaging plasmids, psPAX2 and pMD2.G using Lipofectamine 2000. Forty-eight hours after transfection, the supernatant was collected and lentiviral particles were purified by ultra-centrifugation $(26,000$ $\mathrm{rpm}, 90 \mathrm{~min}$ at $4^{\circ} \mathrm{C}$ ). Titers were determined using HIV-1 p24 antigen ELISA Kit (ZeptoMetrix) as per the manufacturer's instructions.

\section{RT-PCR}

Fresh DMS tissues from individual animals were dissected and homogenized on ice in $300 \mu \mathrm{l}$ of the Paris Kit cell-disruption buffer, and $150 \mu \mathrm{l}$ of the lysate was used for total RNA extraction according to the manufacturer's instructions. A total of $500 \mathrm{ng}$ of mRNA was selectively reverse transcribed (RT) using the RT System Kit. The RT product was used for PCRs using following primers: PTP $\alpha$ : (forward) $5^{\prime}$ - ACAAGATGCG TACGGGAAAC-3', (reverse) 5'-GGACTTCCATTCCCAGATCA-3'; GAPDH: (forward) 5'-TGAAGGTCGGTGTGAACGGATTTGGC-3', (reverse) 5'-CATGTAGGCCATGAGGTCCACCAC-3'. The PCRs were performed using an annealing temperature of $58^{\circ} \mathrm{C}$, for $28-32$ cycles. The PCR product was separated on $1.5 \%$ agrose gels, photographed by Image Lab, and quantified by using ImageJ.

\section{Synaptosomal membrane preparation}

Crude synaptosomal membranes were prepared as described previously (Gibb et al., 2011). Briefly, immediately after being collected, DMS tissue from individual mice was homogenized in a glass homogenizer containing $500 \mu \mathrm{l}$ of ice-cold Krebs-sucrose buffer (in mM as follows: $125 \mathrm{NaCl}$, 1.2 KCl, 1.2 $\mathrm{MgSO}_{4}, 1.2 \mathrm{CaCl}_{2}, 22 \mathrm{Na}_{2} \mathrm{CO}_{3}, 1.2 \mathrm{NaH}_{2} \mathrm{PO}_{4}, 10$ glucose, and 320 sucrose, $\mathrm{pH} 7.4$ ) in the presence of protease and phosphatase inhibitors. The homogenate was centrifuged at $1000 \times g$ for $10 \mathrm{~min}$ at $4^{\circ} \mathrm{C}$ to pellet heavy membranes and debris. The supernatant was collected and centrifuged at $16,000 \times g$ at $4^{\circ} \mathrm{C}$ for 20 min to pellet the crude synaptosomal membrane fraction (synaptosome fraction). The synaptosome fraction was resuspended in $100 \mu$ l RIPA. Total protein concentration was determined using the BCA protein assay kit.

\section{Western blot analysis}

Equal amounts of homogenates from individual rats or mice (30 $\mu \mathrm{g})$ were resolved on NuPAGE 10\% Bis-Tris gels and transferred onto nitrocellulose membranes. Blots were blocked with 5\% milk-PBST, then probed with antiPTP $\alpha$ (1:500), anti-[pY1472]GluN2B (1:250), anti-[pY418/420]Src/Fyn (1: $500)$, anti-actin (1/1000), or anti-GAPDH (1:2000) antibodies overnight at $4^{\circ} \mathrm{C}$. Membranes were then washed and probed with HRP-conjugated secondary antibodies for $2 \mathrm{~h}$ at room temperature. Membranes were then stripped for $30 \mathrm{~min}$ at room temperature in a buffer containing $25 \mathrm{~mm}$ glycine-HCl, $1 \%(\mathrm{w} / \mathrm{v})$ SDS, $\mathrm{pH} 3.0$, and reprobed with anti-GluN2B or anti-Fyn antibodies. Membranes were visualized using ECL. Band intensities were quantified by ImageJ.

\section{Immunochemistry}

Animals were deeply anesthetized with an overdose of Euthasol and perfused with $0.9 \% \mathrm{NaCl}$, followed by $4 \%$ paraformaldehyde in PBS, $\mathrm{pH}$ 7.4. Brains were removed, postfixed in the same fixative for $2 \mathrm{~h}$, and transferred to PBS at $4^{\circ} \mathrm{C}$. On the following day, brains were transferred into $30 \%$ sucrose and stored for $3 \mathrm{~d}$ at $4^{\circ} \mathrm{C}$. Frozen, $50-\mu \mathrm{m}$-thick coronal sections were cut on a cryostat (Microm, Thermo Fisher Scientific), collected in 24-well plates, and stored in PBS at $4^{\circ} \mathrm{C}$. Free-floating sections containing the infusion site in the striatum were selected, permeabilized with $50 \%$ ethanol for $10 \mathrm{~min}$, and rinsed in PBS. Sections were then blocked with $10 \%$ normal donkey serum in PBS for $30 \mathrm{~min}$ and incubated for $48 \mathrm{~h}$ at $4^{\circ} \mathrm{C}$ on an orbital shaker with antibodies for either the neuronal marker (anti-NeuN antibodies, 1:500) or the glial marker (antiGFAP antibodies, 1:1000) in combination with anti-GFP antibodies (1: $10,000)$ diluted in PBS/0.05\% Triton X-100. Next, sections were washed in PBS, incubated with $2 \%$ normal donkey serum for $10 \mathrm{~min}$, and incubated for $4 \mathrm{~h}$ with the secondary antibodies: AlexaFluor-488-labeled donkey anti-rabbit and AlexaFluor-594-labeled donkey anti-mouse (both 1:300) antibodies. After staining, sections were rinsed in PBS and coverslipped using Vectashield mounting medium. Images were acquired using Zeiss LSM 510 META laser confocal microscope (Zeiss MicroImaging) using manufacture recommended filter configurations.

\section{Slice preparation and electrophysiology}

Slice preparation. Coronal sections of the striatum $(300 \mu \mathrm{m})$ were cut in an ice-cold solution containing the following (in $\mathrm{mm}$ ): $40 \mathrm{NaCl}, 143.5$ sucrose, $4 \mathrm{KCl}, 1.25 \mathrm{NaH}_{2} \mathrm{PO}_{4}, 26 \mathrm{NaHCO}_{3}, 0.5 \mathrm{CaCl}_{2}, 7 \mathrm{MgCl}_{2}, 10$ glucose, 1 sodium ascorbate, and 3 sodium pyruvate, saturated with $95 \%$ $\mathrm{O}_{2}$ and $5 \% \mathrm{CO}_{2}$. Slices were then incubated in the same solution at $32^{\circ} \mathrm{C}$ for $45 \mathrm{~min}$ and were then transferred to a chamber that contained an external solution composed (in $\mathrm{mm}$ ) as follows: $125 \mathrm{NaCl}, 2.5 \mathrm{KCl}, 2.5$ $\mathrm{CaCl}_{2}, 1.3 \mathrm{MgCl}_{2}, 1.25 \mathrm{NaH}_{2} \mathrm{PO}_{4}, 25 \mathrm{NaHCO}_{3}$, and 10 glucose, saturated with $95 \% \mathrm{O}_{2}$ and $5 \% \mathrm{CO}_{2}$. Slices were stored in the external solution at room temperature until use.

Whole-cell recording. NMDAR-mediated EPSCs were measured using voltage-clamp recording as described previously (Wang et al., 2007, 2010). Specifically, fluorescent neurons in the DMS were clamped at $-70 \mathrm{mV}$ with $0.05 \mathrm{~mm}$ external $\mathrm{Mg}^{2+}$ to reduce the $\mathrm{Mg}^{2+}$ blockade of NMDAR channels. $100 \mu \mathrm{M}$ picrotoxin and $10 \mu \mathrm{M}$ NQBX were included in the external solution to block $\mathrm{GABA}_{\mathrm{A}}$ and AMPA receptors, respectively. Electrodes (4-6 M $\Omega$ ) contained the following (in mM): 115 cesium methanesulfonate, 15 HEPES, 0.6 EGTA, 8 TEA-Cl, 4 MgATP, 0.3 NaGTP, and $7 \mathrm{Na}_{2} \mathrm{CrPO}_{4}$ (pH 7.2-7.3) with an osmolarity of $270-280 \mathrm{mOsm}$. To measure the intrinsic features of 
DMS neurons whole-cell current-clamp recording was used. Cesium methanesulfonate was replaced with potassium methanesulfonate. Resting membrane potentials of DMS neurons were measured $3 \mathrm{~min}$ after the whole-cell configuration was established, and the membrane potentials were kept at $-70 \mathrm{mV}$ for other measurements. Neurons were then injected through patching pipette with a series of $1 \mathrm{~s} \mathrm{step} \mathrm{currents,} \mathrm{starting} \mathrm{from}-210 \mathrm{pA}$ and in increments of $15 \mathrm{pA}$ (for constructing current-voltage curves) or $10 \mathrm{pA}$ (for measuring rheobase currents). The rheobase current was defined as the first current step capable of eliciting one action potential (Gertler et al., 2008).

\section{Lentiviral infection of the DMS in rats and mice}

Rats were continuously anesthetized with isoflurane (Baxter) during the surgery. Mice were anesthetized using a mixture of ketamine $(120 \mathrm{mg} / \mathrm{kg})$ and xylazine $(8 \mathrm{mg} / \mathrm{kg})$. Bilateral microinfusions were made using stainless steel injectors (33 gauge, Small Parts) into the rat DMS (the stereotaxic coordinates were anterioposterior $+1.4 \mathrm{~mm}$ and $+0.4 \mathrm{~mm}$ from bregma, mediolateral $\pm 1.7 \mathrm{~mm}$ from bregma, and dorsoventral -4.3 and $-5.5 \mathrm{~mm}$ from the skull surface) or into the mice DMS (the stereotaxic coordinates were anterioposterior $+1.6 \mathrm{~mm}$ and $+1.1 \mathrm{~mm}$ from bregma; mediolateral $\pm 1.15 \mathrm{~mm}$ from bregma and dorsoventral -3.0 and $-3.5 \mathrm{~mm}$ from the skull surface). Animals were infused with lentivirus expressing Ltv-shPTP $\alpha$ or Ltv-NS (1.2 $\mu$ l/injection site with 4 sites of injection per hemisphere) at a concentration of $2 \times 10^{7} \mathrm{pg} / \mathrm{ml}$ at an injection rate of $0.1 \mu \mathrm{l} / \mathrm{min}$. After each infusion, the injectors were left in place for an additional $12 \mathrm{~min}$ to allow the virus to diffuse. Rats recovered for 1 week before the intermittent-access $20 \%$ ethanol two bottle choice drinking paradigm was resumed and mice recovered for 3-4 weeks before ethanol-drinking experiment was initiated.

\section{Behavioral experiments in rats}

Intermittent-access $20 \%$ ethanol two bottle choice drinking paradigm. The intermittent-access to $20 \%$ ethanol two bottle choice drinking procedure was conducted as described previously (Carnicella et al., 2009). Briefly, rats were given $24 \mathrm{~h}$ of concurrent access to one bottle of $20 \%$ ethanol $(\mathrm{v} / \mathrm{v})$ in tap water and one bottle of water. The drinking session started at 12:00 P.M. on Monday, Wednesday, and Friday, with 24 or 48 h (weekend) ethanol-deprivation periods between the ethanol-drinking sessions. The placement (left or right) of each solution was alternated between each session to control for side preference. The water and ethanol bottles were weighed $24 \mathrm{~h}$ after the beginning of the session. Six weeks after the beginning of ethanol intake procedure and when rats achieved a stable baseline of ethanol consumption, we assessed the effect of PTP $\alpha$ downregulation on ethanol intake. Ltv-shPTP $\alpha$ or Ltv-NS was infused into the DMS as described above. After 1 week of recovery, the two bottle choice drinking procedure was resumed and the level of ethanol intake and preference were measured for 7 weeks.

\section{Intermittent-access sucrose two bottle choice drinking paradigm}

One week after the end of the ethanol-drinking study, rats were tested for sucrose intake. The procedure was similar to the intermittent-access ethanol two bottle choice drinking paradigm described above, except that a sucrose $(0.2 \%$ or $1.5 \%)$ solution was substituted for ethanol. Each concentration of sucrose was offered for 2 weeks and the amount of fluid intake was recorded every other day.

\section{Behavioral experiments in mice}

Voluntary ethanol consumption. Ltv-shPTP $\alpha$ or Ltv-NS was infused into the DMS of mice. Four weeks later, oral ethanol intake was determined using continuous access to ethanol in a two bottle choice drinking paradigm. Drinking sessions were conducted $24 \mathrm{~h}$ a day, $7 \mathrm{~d}$ a week, with one bottle containing tap water, while the other contained an increasing concentration of ethanol $(3 \%, 6 \%, 10 \%$, and $20 \%)$ with $7 \mathrm{~d}$ of access for each concentration. Fresh fluids were provided each time the concentration was changed. The bottles were weighed on days 2, 4, and 7 of each week, and the mice were weighed once a week. The position (left or right) of each solution was alternated as a control for side preference.

\section{Quinine and saccharin consumption}

One week after the ethanol-drinking study, mice were tested for saccha$\operatorname{rin}(0.066 \%)$ or quinine hemisulfate $(0.06 \mathrm{~mm})$ intake. Each solution was offered for $3 \mathrm{~d}$ and the amount of fluid intake was recorded every day.

\section{Rotarod procedure}

Animals were first trained to remain on a Rotarod (Accurotor; AccuScan Instruments) rotating at $10 \mathrm{rpm}$ for $180 \mathrm{~s}$. On the next day, mice were first tested to ensure they could stay on the Rotarod for $180 \mathrm{~s}$ and then systemically treated with $1.5 \mathrm{~g} / \mathrm{kg}$ of ethanol (i.p.). Mice were tested every $15 \mathrm{~min}$ for $120 \mathrm{~min}$, and the latency to fall from the rod was recorded in each trial.

\section{Loss of righting reflex (LORR) assay}

Mice were administered with ethanol (3.2 g/kg, 20\% v/v solution, i.p.); and when they became ataxic, they were placed in a supine position. The loss and recovery of the righting reflex were defined as the inability or ability of the mouse to right itself at least 3 times within $1 \mathrm{~min}$.

Assessment of spontaneous locomotor activity in rats and mice Three days after the end of the sucrose-drinking study (rats) or 1 week after the end of the LORR experiment (mice), the spontaneous locomotor activity was measured in activity-monitoring chambers $(43 \mathrm{~cm} \times 43$ $\mathrm{cm}$ for rats and mice) with horizontal photo beams (Med Associates). Horizontal locomotor activity was monitored, and the distance traveled (cm) by the animals was recorded for $1 \mathrm{~h}$ (rats) or $30 \mathrm{~min}$ (mice).

\section{Histology}

Mice and rats infused with Ltv-shPTP $\alpha$ or Ltv-NS received pentobarbital (i.p.) followed by transcardial perfusion with $4 \%$ PFA. For each subject, the infected area was verified in $50 \mu \mathrm{m}$ coronal sections using Zeiss LSM 510 META laser confocal microscope. Animals showing localized infection in the DMS were included in the studies.

\section{Statistical analysis}

Biochemical data were analyzed using unpaired $t$ test or two-way ANOVA. Behavioral and electrophysiological data were analyzed with unpaired $t$ test or two-way ANOVA with or without repeated measures (RM-ANOVA). Significant main effects and interactions of the ANOVAs were further investigated with the Student-Newman-Keuls (SNK) post hoc test or method of contrast analysis. Statistical significance was set at $p<0.05$.

\section{Results}

\section{PTP $\alpha$ in the DMS contributes to ethanol-drinking behaviors} in rats

We previously showed that PTP $\alpha$ in the DMS is positioned near its substrate Fyn in response to rat binge drinking of ethanol (Gibb et al., 2011). We further showed that PTP $\alpha$ is phosphorylated in response to ethanol exposure (Gibb et al., 2011), which indicates an increase in phosphatase activity (den Hertog et al., 1994; Chen et al., 2006). To determine whether PTP $\alpha$, being upstream of Fyn, contributes to ethanol-related behaviors, we knockdown the expression of the phosphatase specifically in the DMS and examined the level of ethanol intake.

To do so, first we generated a lentivirus expressing shRNA sequence targeting PTP $\alpha(\mathrm{Ltv}-\operatorname{shPTP} \alpha)$ and enhanced green fluorescent protein (EGFP) as a marker, as well as a virus expressing a nonspecific sequence (Ltv-NS) and EGFP. Infection of differentiated SH-SY5Y cells with Ltv-shPTP $\alpha\left(2 \times 10^{5} \mathrm{pg} / \mathrm{ml}\right)$ significantly reduced the levels of PTP $\alpha$ mRNA compared with cells treated with Ltv-NS (decrease of $87.46 \pm 4.33 \%, t_{(3)}=13.03, p<$ $0.001, n=2-3$ ). Next, Ltv-shPTP $\alpha$ or Ltv-NS was stereotaxically administered into the DMS of adult rats, and lentivirus infection and gene knockdown were examined 6 weeks later. As shown in Figure $1 A$, infusion of Ltv-shPTP $\alpha$ into the DMS resulted in a high level of infection exclusively in neurons (Fig. 1A, NeuN [top panels] vs GFAP [bottom panels]). Infection of DMS neurons resulted in a significant knockdown of $P T P \alpha$ mRNA (Fig. $1 B ; t_{(6)}=$ 4.92, $p=0.003$ ) and protein levels (Fig. $1 C ; t_{(5)}=2.81, p=0.04$ ) compared with the levels in the DMS of rats infected with the control Ltv-NS. Infusion of Ltv-shPTP $\alpha$ into the DMS of rats did not 
A
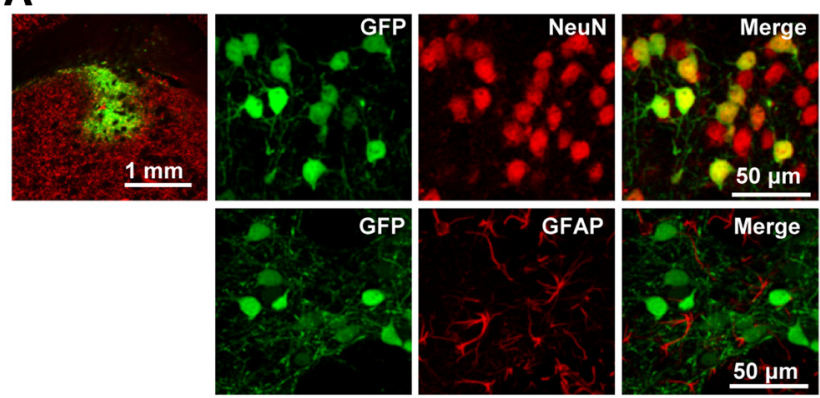

B

$\square$ Ltv-NS $\square$ Ltv-shPTPalpha
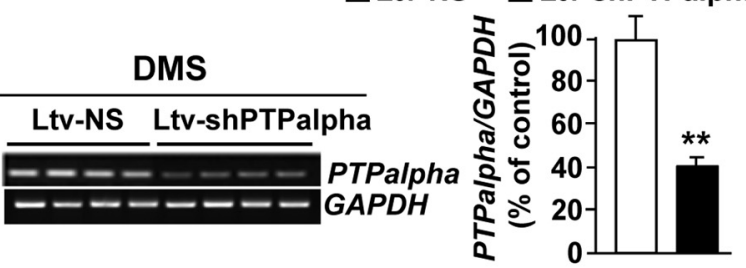

C

DMS
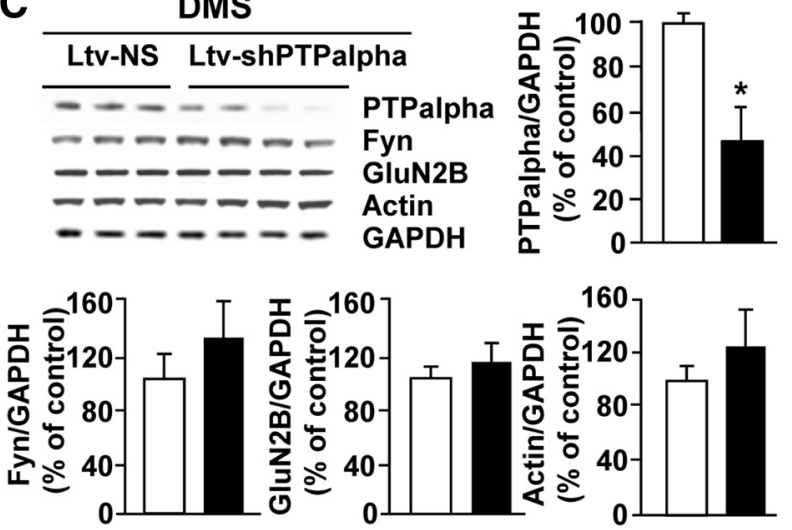

\section{D}
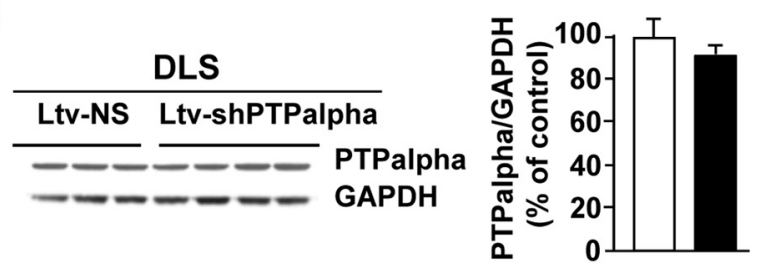

Figure 1. Infection of rat DMS neurons with a Ltv-shPTP $\alpha$ produces downregulation of the expression of the phosphatase. Recombinant Ltv-shPTP $\alpha$ or a Ltv-NS was bilaterally infused at a titer of $2 \times 10^{7} \mathrm{pg} / \mathrm{ml}$ into the DMS of rats. Striatal tissues were collected 6 weeks after virus infusions and used for immunohistochemistry $(\boldsymbol{A}), \mathrm{RT}-\mathrm{PCR}(\boldsymbol{B})$, and Western blot $(\boldsymbol{C}, \boldsymbol{D})$ analysis. $A$, Ltv-shPTP $\alpha$ infects DMS neurons. Top left, Specificity of the site of infection. Slices were costained with anti-GFP and anti-NeuN antibodies. Scale bar, $1 \mathrm{~mm}$. Right, Costaining of GFP with NeuN (top) or GFAP (bottom). Scale bar, $50 \mu \mathrm{m}$. $\boldsymbol{B}-\boldsymbol{D}$, Ltv-shPTP $\alpha$ infection in the DMS decreases the mRNA (B) and protein levels $(\boldsymbol{C})$ of PTP $\alpha$ in the DMS but not in the DLS (D). Ltv-shPTP $\alpha$ infection in the DMS does not change the protein levels of Fyn, GluN2B, or actin (C). GAPDH immunoreactivity was used as an internal loading control. Histograms represent the mean ratio of PTP $\alpha$, Fyn, GluN2B, or actin/GAPDH \pm SEM. Data are expressed as the percentage of control (Ltv-NS infected mice). ${ }^{*} p<0.05$ (two-tailed unpaired $t$ test). ${ }^{* *} p<0.01$ (twotailed unpaired $t$ test). $\boldsymbol{B}, n=4$. $\boldsymbol{C}, \boldsymbol{D}, n=3-4$ for each group.

affect the levels of Fyn (Fig. $1 C ; t_{(5)}=-1.68, p>0.05$ ), GluN2B (Fig. $1 C ; t_{(5)}=-1.23, p>0.05$ ), or actin (Fig. $1 C ; t_{(5)}=$ $-1.48, p>0.05)$, and the levels of PTP $\alpha$ in the DLS were also unaltered (Fig. $\left.1 D ; t_{(5)}=0.98, p>0.05\right)$.

Next, we tested whether PTP $\alpha$ in the DMS of rats plays a role in the maintenance and/or the expression of excessive ethanol intake. Animals were first trained to consume $20 \%$ ethanol for 2

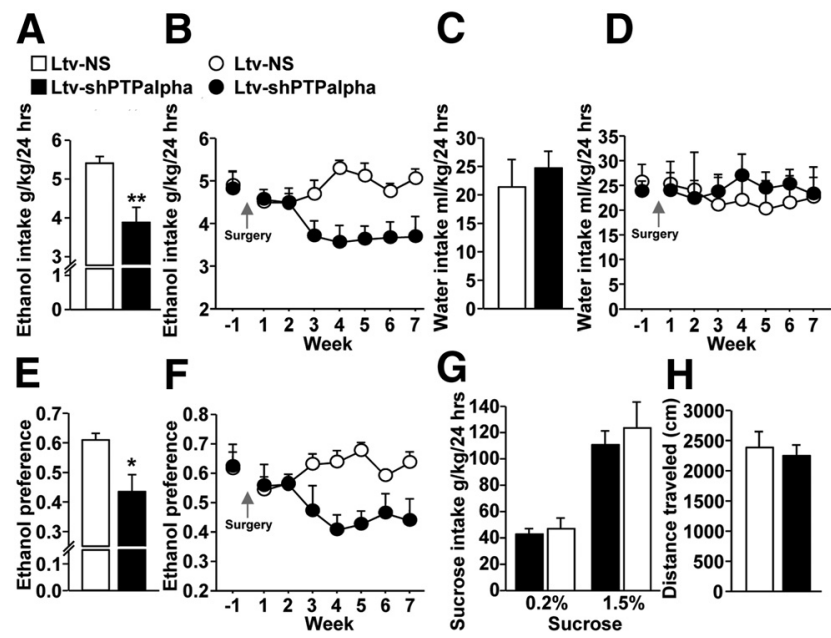

Figure 2. Knockdown of PTP $\alpha$ in the DMS of rats reduces excessive ethanol but not water or sucrose intake without altering locomotion. Rats were trained to consume a $20 \%$ ethanol solution in an intermittent access two bottle choice drinking paradigm. Animals were given $24 \mathrm{~h}$ of concurrent access to one bottle of $20 \%$ ethanol $(\mathrm{v} / \mathrm{v})$ and one bottle of water every other day for 6 weeks. After a stable baseline level of excessive ethanol intake was established, Ltv-shPTP $\alpha$ or the control virus Ltv-NS were infused into the rat DMS. One week after virus infusion, the two bottle choice drinking procedure was resumed, and levels of ethanol and water intake, as well as preference for the ethanol solution over water were measured. Average of ethanol $(\boldsymbol{A})$ and water $(\boldsymbol{C})$ intake, and ethanol preference $(\boldsymbol{E})$ in a $24 \mathrm{~h}$ drinking session during the last month of the experiment (from week 4 to week 7). Average of ethanol $(\boldsymbol{B})$ and water $(\boldsymbol{D})$ intake, and ethanol preference $(\boldsymbol{F})$ in a $24 \mathrm{~h}$ drinking session per week over 8 weeks (one week before and 7 weeks after virus infusion). $\boldsymbol{A}, \boldsymbol{B}$, Average of $24 \mathrm{~h}$ ethanol consumption per month $(\boldsymbol{A})$ and per week $(\boldsymbol{B})$. C, D, Average $24 \mathrm{~h}$ water intake per month $(\boldsymbol{C})$ and per week $(\boldsymbol{D}) . \boldsymbol{E}, \boldsymbol{F}$, Average of ethanol preference per $24 \mathrm{~h}$ drinking session per month $(\boldsymbol{E})$ and per week $(\boldsymbol{F})$. Ethanol preference was calculated as the percentage of ethanol solution consumed in $24 \mathrm{~h}$ relative to total fluid intake (ethanol + water). G, Downregulation of PTP $\alpha$ in the rat DMS does not affect sucrose intake. One week after the end of the ethanol drinking experiment, rats were tested for sucrose intake in an intermittent access two bottle choice drinking procedure. Each concentration of sucrose ( $0.2 \%$ and $1.5 \%$ ) was tested for 2 weeks. Shown is an average of sucrose intake in a $24 \mathrm{~h}$ drinking session. $\boldsymbol{H}$, Knockdown of PTP $\alpha$ in the DMS of rats does not affect locomotor activity. Three days after the end of sucrose experiments, animals were tested for spontaneous locomotor activity. Rats were placed in locomotor activity chambers, and the distance traveled was recorded for $1 \mathrm{~h}$. Data represent the cumulative locomotor activity $(\mathrm{cm})$ during the testing period. Data are mean \pm SEM. ${ }^{*} p<0.05$ (two-way RM-ANOVA with SNK post hoc test and two-tailed unpaired $t$ test). ${ }^{* *} p<0.01$ (two-way RM-ANOVA with SNK post hoc test and two-tailed unpaired $t$ test). $n=7$ or 8 for each group.

months using the intermittent two bottle choice procedure (Carnicella et al., 2009). After establishing a stable ethanol drinking level of $\sim 5 \mathrm{~g} / \mathrm{kg} / 24 \mathrm{~h}$, rats were infused with Ltv-shPTP $\alpha$ or Ltv-NS in the DMS. The intermittent two bottle choice drinking procedure was resumed a week later, and ethanol intake and preference were measured at the end of each ethanol drinking session. As shown in Figure $2 A, B$, knockdown of PTP $\alpha$ in the DMS produced a robust reduction of ethanol intake compared with rats infected with Ltv-NS (Fig. $2 A ; t_{(13)}=3.89, p=0.002$; Fig. $2 B$; two-way RMANOVA), significant main effect of Ltv-shPTP $\alpha$ infusion $\left(F_{(1,91)}=\right.$ $6.66, p=0.023)$, no significant effect of weeks $\left(F_{(7,91)}=1.68, p>\right.$ $0.05)$, and a significant interaction between Ltv-shPTP $\alpha$ infusion $X$ weeks $\left(F_{(7,91)}=5.12, p<0.001\right)$. SNK post hoc test revealed a significant difference in ethanol intake from weeks 3-7 between rats infused with Ltv-shPTP $\alpha$ and those infected with Ltv-NS $(p<0.05)$. Importantly, PTP $\alpha$ knockdown in the DMS did not change water intake (Fig. $2 C$; $t_{(13)}=-0.50, p>0.05$; Fig. $2 D$; two-way RMANOVA), no effect of Ltv-shPTP $\alpha$ infusion $\left(F_{(1,91)}=0.05, p>\right.$ $0.05)$, no effect of weeks $\left(F_{(7,91)}=0.50, p>0.05\right)$, and no interaction between Ltv-shPTP $\alpha$ infusion $\times$ weeks $\left(F_{(7,91)}=1.02, p>0.05\right)$, but 
A
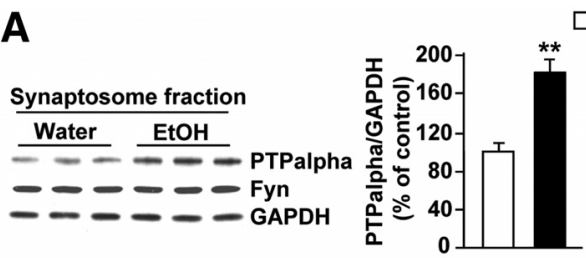

$\square$ Water $\square$ EtOH

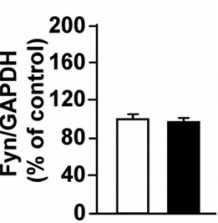

B
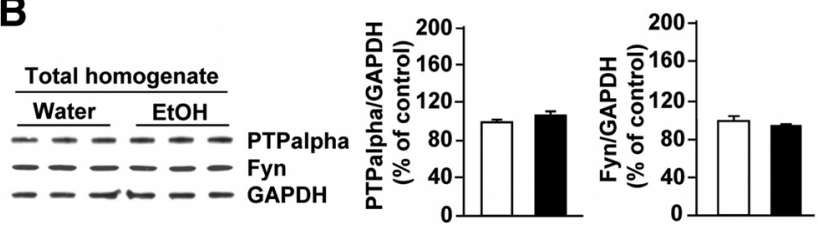

Figure 3. Ethanol consumption compartmentalizes PTP $\alpha$ in the synaptosomal fraction of the DMS of mice. Mice had continuous access to $10 \%$ ethanol for $21 \mathrm{~d}$ in a two bottle choice paradigm. At the end of the last $24 \mathrm{~h}$ ethanol drinking session, DMS tissue was collected and the protein levels of PTP $\alpha$ (top) and Fyn (middle) in synaptosomal fraction ( $\boldsymbol{A}$ ) and in the total homogenate $(\boldsymbol{B})$ were measured. Control animals underwent the same paradigm but had access to water only. GAPDH immunoreactivity was used as an internal loading control. Histograms represent the mean ratio of PTP $\alpha$ or Fyn/GAPDH \pm SEM, and data are expressed as the percentage of control (mice with access only to water). ${ }^{* *} p<0.01$ (two-tailed unpaired $t$ test). $n=3$.

reduced the preference for ethanol versus water (Fig. $2 E ; t_{(13)}=2.98$, $p=0.01$; Fig. $2 F$; two-way RM-ANOVA), a significant main effect of Ltv-shPTP $\alpha$ infusion $\left(F_{(1,91)}=5.21, p=0.04\right)$, no significant effect of weeks $\left(F_{(7,91)}=0.91, p>0.05\right)$, and a significant interaction between Ltv-shPTP $\alpha$ infusion $\times$ weeks $\left(F_{(7,91)}=3.05, p=0.006\right)$. SNK Post hoc test revealed a significant difference in ethanol preference during weeks 3, 4, 5, and 7 between rats infused with Ltv$\operatorname{shPTP} \alpha$ and the control group infused with Ltv-NS $(p<0.05)$.

To determine whether the reduction of excessive ethanol intake in rats infused with Ltv-shPTP $\alpha$ was not the result of alteration of general reward, one week after the end of the ethanol intake experiment, daily drinking of a naturally reinforcing substance, sucrose, was measured. As shown in Figure 2G, downregulation of PTP $\alpha$ in the DMS of rats did not alter consumption of low $(0.2 \%)\left(t_{(13)}=-0.60, p>0.05\right)$ or high $(1.5 \%)\left(t_{(13)}=\right.$ $-0.84, p>0.05)$ concentrations of sucrose. In addition, to confirm that the reduction of ethanol intake in response to PTP $\alpha$ knockdown in the DMS was not the result of alterations in locomotion, we measured spontaneous locomotor activity in an open field test. No differences were observed between rats infected with Ltv-shPTP $\alpha$ and those infected with Ltv-NS (Fig. $2 H ; t_{(13)}=0.96$, $p>0.05)$. These results suggest that downregulation of PTP $\alpha$ in the DMS reduces ethanol consumption without affecting the brain's natural reward system or general motor activity performance. Furthermore, these data indicate that PTP $\alpha$ in the DMS of rats contributes to mechanisms underlying the maintenance and/or expression of high ethanol intake.

PTP $\alpha$ in the DMS contributes to ethanol-drinking behaviors in mice

Next, we set out to test whether the contribution of PTP $\alpha$ to ethanol drinking behaviors is conserved across species. First, we confirmed that, similar to results previously obtained in rats (Gibb et al., 2011), voluntary consumption of ethanol in mice results in the movement of PTP $\alpha$ to synaptic membranes (Fig. $3 A$, bar graph, middle; synaptosome fraction: $t_{(4)}=5.13, p=$ 0.007; Fig. $3 B$, bar graph, middle; total homogenate: $t_{(4)}=1.44$, $p>0.05$ ), the compartment where Fyn resides (Fig. $3 A$, bar graph, right; synaptosome fraction: $t_{(4)}=0.53, p>0.05$; Fig. $3 B$,

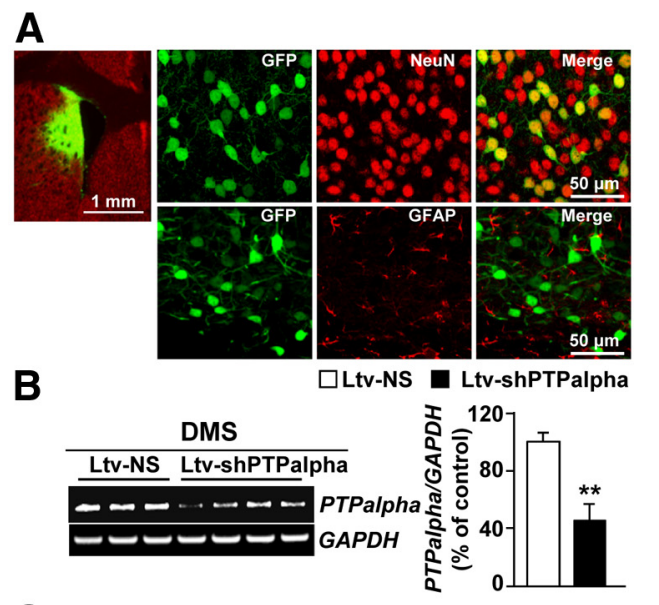

C
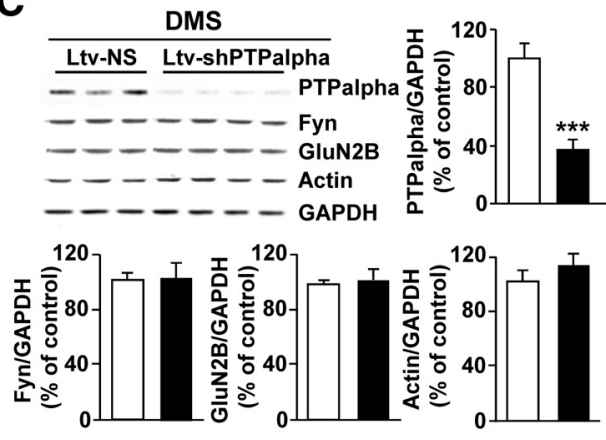

D
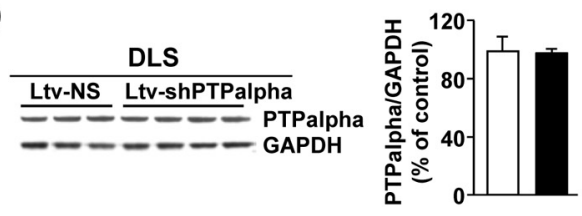

Figure 4. Infection of mouse DMS neurons with Ltv-shPTP $\alpha$ produces a knockdown of the expression of the phosphatase. Recombinant lentivirus containing Ltv-shPTP $\alpha$ or Ltv-NS was bilaterally infused at a titer of $2 \times 10^{7} \mathrm{pg} / \mathrm{ml}$ into the DMS of mice. Striatal tissues were collected 4 weeks after virus infusions and used for immunohistochemistry $(\boldsymbol{A})$, RT-PCR $(\boldsymbol{B})$, and Western blot $(\boldsymbol{C}, \boldsymbol{D})$ analysis. $\boldsymbol{A}$, Ltv-shPTP $\alpha$ infects DMS neurons. Slices were costained with anti-GFP and anti-NeuN antibodies. Left, Specificity of the infection site. Scale bar, $1 \mathrm{~mm}$. Right, Costaining of GFP with NeuN (top) or GFAP (bottom). Scale bar, $50 \mu \mathrm{m}$. $\boldsymbol{B}-\boldsymbol{D}$, Ltv-shPTP $\alpha$ decreases the mRNA (B) and protein level ( $\boldsymbol{C}$ ) of PTP $\alpha$ in the DMS but not the DLS $(\boldsymbol{D})$. Ltv-shPTP $\alpha$ infection in the DMS does not change the protein levels of Fyn, GluN2B, or actin (C). GAPDH immunoreactivity was used as an internal loading control. Histograms represent the mean ratio of PTP $\alpha$, Fyn, GluN2B, or actin/GAPDH \pm SEM. Data are expressed as the percentage of control (Ltv-NS-infected mice). ${ }^{* *} p<0.01$ (two-tailed unpaired $t$ test). ${ }^{* * *} p<0.001$ (two-tailed unpaired $t$ test). $B-D, n=3-4$ for each group.

bar graph, right; total homogenate: $\left.t_{(4)}=0.98, p>0.05\right)$. Next, we verified that infection of mouse DMS neurons with Ltv$\operatorname{shPTP} \alpha$ downregulates the level of the phosphatase. As shown in Figure 4, infusion of Ltv-shPTP $\alpha$ into the DMS of mice resulted in a high level of infection exclusively in neurons (Fig. $4 A$, NeuN [top panels] vs GFAP [bottom panels]). Importantly, the levels of $P T P \alpha$ mRNA (Fig. $4 B ; t_{(5)}=3.75, p=0.01$ ) and protein (Fig. $4 C$; $\left.t_{(5)}=7.81, p<0.001\right)$ were robustly decreased in the DMS of mice infected with Ltv-shPTP $\alpha$ compared with animals infected with LtvNS; however, the levels of Fyn (Fig. $4 C$; $t_{(5)}=-0.38, p>0.05$ ), GluN2B (Fig. $4 C$; $t_{(5)}=-0.62, p>0.05$ ), and actin (Fig. $4 C$; $t_{(5)}=$ $-2.02, p>0.05)$ were unaltered in the DMS. Notably, infection of mouse DMS neurons with Ltv-shPTP $\alpha$ did not alter the level of the phosphatase in the DLS (Fig. $4 D ; t_{(5)}=0.16, p>0.05$ ). 

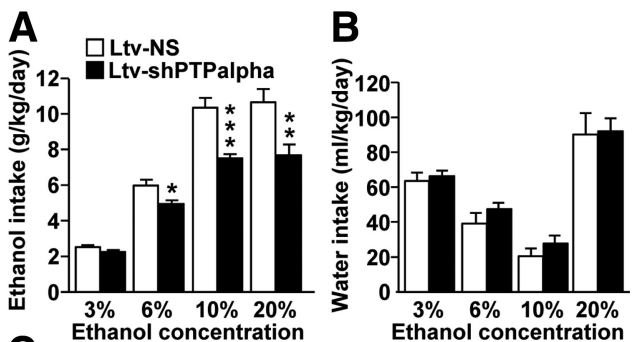

C
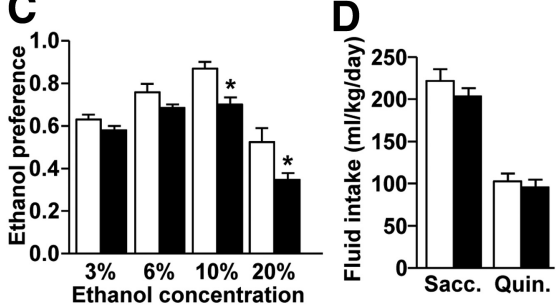

Figure 5. Knockdown of PTP $\alpha$ in the mouse DMS reduces ethanol but not water intake. $A-C$, Knockdown of PTP $\alpha$ in the DMS of mice reduces ethanol intake. Mice were infused with Ltv-shPTP $\alpha$ or Ltv-NS in the DMS. Four weeks later, animals were tested in a continuous access two bottle choice drinking protocol. Mice were allowed access to a bottle containing an ethanol solution and a bottle of tap water for 4 weeks. Ethanol concentrations were progressively increased from $3 \%$ to $20 \%(3 \%, 6 \%, 10 \%$, and $20 \%)$ ethanol with $7 \mathrm{~d}$ access for each concentration. $\boldsymbol{A}$, Average of daily ethanol intake. $\boldsymbol{B}$, Average of daily water intake. $\boldsymbol{C}$, Average of daily ethanol preference per week. Ethanol preference was calculated as the percentage of ethanol solution consumed relative to total fluid intake (ethanol + water). D, Knockdown of PTP $\alpha$ in the DMS of mice does not alter intake of saccharin or quinine. Animals had access to saccharine $(0.066 \%)$ or quinine $(0.06 \mathrm{~mm})$ in a continuous access two bottle choice drinking protocol. Each solution was provided for 3 consecutive days. Group data represent mean \pm SEM. ${ }^{*} p<0.05$ (two-way ANOVA with SNK post hoc test). ${ }^{* *} p<0.01$ (two-way ANOVA with SNK post hoc test). ${ }^{* *} p<0.001$ (two-way ANOVA with SNK post hoc test). $n=10-12$ for each group.

Next, we tested the consequence of PTP $\alpha$ downregulation in the DMS on ethanol intake. Four weeks after viral infusion, mice were trained to drink ethanol in a continuous two bottle choice protocol. As shown in Figure 5A, knockdown of PTP $\alpha$ resulted in a robust reduction of daily ethanol intake; two-way ANOVA analysis showed a significant effect of Ltv-shPTP $\alpha$ infusion $\left(F_{(1,57)}=29.54, p<\right.$ $0.001)$, a significant effect of ethanol concentration $\left(F_{(3,57)}=146.93\right.$, $p<0.001$ ), and a significant interaction between Ltv-shPTP $\alpha$ infusion $\times$ ethanol concentration $\left(F_{(3,57)}=6 \cdot 10, p<0.001\right)$. SNK post hoc test revealed that mice infused with Ltv-shPTP $\alpha$ drank less ethanol at the $6 \%, 10 \%$, and $20 \%$ concentrations compared with those infused with Ltv-NS $(p<0.05)$. No significant difference in daily water intake was observed (Fig. 5B); two-way ANOVA analysis showed no effect of Ltv-shPTP $\alpha$ infusion $\left(F_{(1,57)}=1.20, p>0.05\right)$, a significant effect of ethanol concentration $\left(F_{(3,57)}=75.86, p<\right.$ 0.001 ), and no interaction between Ltv-shPTP $\alpha$ infusion $\times$ ethanol concentration $\left(F_{(3,57)}=0.25, p>0.05\right)$. Finally, mice infused with Ltv-shPTP $\alpha$ in the DMS showed a significant reduction in ethanol preference compared with those infused with Ltv-NS (Fig. 5C); twoway ANOVA showed a significant effect of Ltv-shPTP $\alpha$ infusion $\left(F_{(1,57)}=10.24, p=0.005\right)$, a significant effect of ethanol concentration $\left(F_{(3,57)}=68.66, p<0.001\right)$, and no interaction between LtvshPTP $\alpha$ infusion $\times$ ethanol concentration $\left(F_{(3,57)}=1.99, p>0.05\right)$. Further analysis by the method of contrasts revealed a significant difference in ethanol preference for the $10 \%$ and $20 \%$ concentrations between the two groups of mice $(p<0.05)$.

We then determined whether the reduction in ethanol intake and preference in response to PTP $\alpha$ knockdown were the result of nonspecific behavioral alterations, including consummatory behaviors, taste palatability, motor coordination, or spontaneous loco-
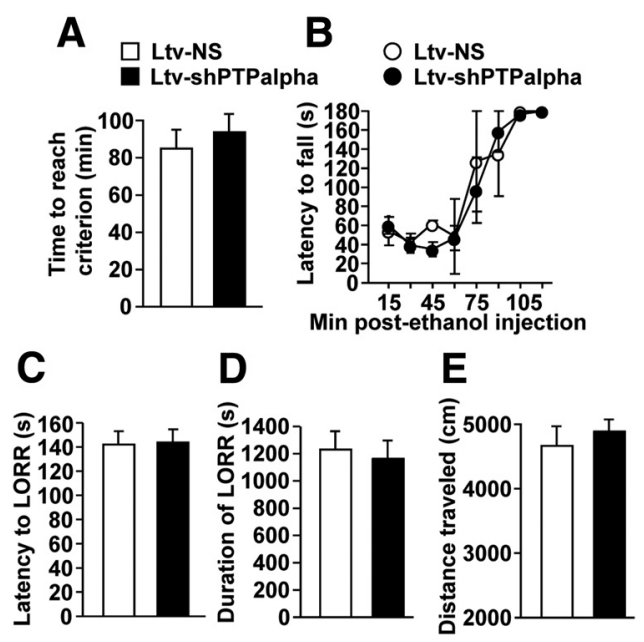

Figure 6. Downregulation of PTP $\alpha$ expression in the DMS of mice does not alter motor coordination, ethanol-induced LORR, and spontaneous locomotor activity in mice. Experiments were conducted at the end of the drinking experiments described in the legend of Figure 5.A, $\boldsymbol{B}$, Rotarod test. On the first day of the experiment, the time to reach $180 \mathrm{~s}$ criterion was recorded $(\boldsymbol{A})$. One day later, animals were administered ethanol $(1.5 \mathrm{~g} / \mathrm{kg})$ and placed and latency to fall from the rotarod was recorded every $15 \mathrm{~min}(\boldsymbol{B}) . \boldsymbol{C}, \boldsymbol{D}$, LORR test. Three days after the Rotarod test, mice were given $3.2 \mathrm{~g} / \mathrm{kg}$ ethanol and the latency to $(\boldsymbol{C})$ and duration of $(\boldsymbol{D})$ the LORR were recorded. $\boldsymbol{E}$, Knockdown of PTP $\alpha$ in the DMS of mice does not affect spontaneous locomotor activity. One week after the end of the LORR experiment, animals were tested for spontaneous locomotor activity. Mice were placed in locomotor activity chambers, and the distance traveled was recorded for $30 \mathrm{~min}$. Data are presented as cumulative locomotor activity $(\mathrm{cm})$ during the testing period. Data are mean \pm SEM. $\boldsymbol{A}, \boldsymbol{B}, n=6-9$ for each group. $\boldsymbol{C}, \boldsymbol{D}, n=6-8$ for each group. $\boldsymbol{E}, n=10-12$ for each group.

motor activity. As shown in Figure $5 D$, mice infected with LtvshPTP $\alpha$ or Ltv-NS consumed similar amounts of saccharin (sweet) $\left(t_{(19)}=1.08, p>0.05\right)$ and quinine (bitter) $\left(t_{(19)}=1.65, p>0.05\right)$ solutions. Furthermore, downregulation of PTP $\alpha$ in the DMS did not produce changes in locomotor coordination in a rotarod procedure in the presence or absence of ethanol (Fig. $6 A, B ; t_{(12)}=-0.97$, $p>0.05)$. In addition, we assessed the sensitivity of mice to the hypnotic effects of ethanol by measuring ethanol-induced LORR. Animals were given a systemic administration of a high dose of ethanol $(3.2 \mathrm{~g} / \mathrm{kg})$, and the latency and duration of the LORR were recorded. As shown in Figure $6 C, D$, no differences were observed in either the latency (Fig. $6 C ; t_{(13)}=-0.116, p>0.05$ ) or the duration (Fig. $6 D ; t_{(13)}=0.35, p>0.05$ ) of LORR between the two groups of mice. Finally, we tested whether downregulation of PTP $\alpha$ in the DMS alters spontaneous locomotor activity. No differences were observed between the two groups of mice (Fig. $6 E ; t_{(19)}=0.65, p>$ 0.05). Together, these results indicate that, similar to rats, PTP $\alpha$ knockdown in the DMS of mice produces a specific reduction in excessive ethanol intake, which is not the result of a general behavioral impairment. Together, these data indicate that PTP $\alpha$ in the DMS of mice contributes to mechanisms underlying acquisition and/or maintenance of excessive ethanol drinking behavior.

\section{Ethanol-mediated Fyn activation and GluN2B phosphorylation are attenuated in the DMS upon PTP $\alpha$ knockdown}

Next, we hypothesized that, if PTP $\alpha$ is upstream of Fyn in the DMS, then knockdown of the phosphatase should reduce ethanol-induced activation of Fyn. To test this hypothesis, the DMS of mice was infected with Ltv-shPTP $\alpha$ or Ltv-NS. Four weeks later, animals were administered systemically with ethanol $(2.5 \mathrm{~g} / \mathrm{kg})$ or saline. Fifteen minutes later, levels of Fyn activity 
A

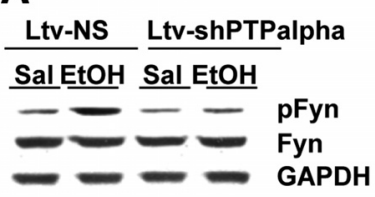

B

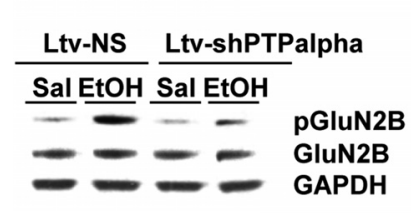

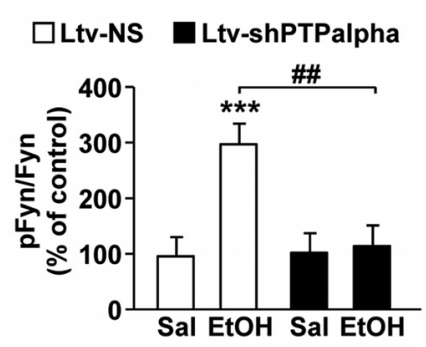

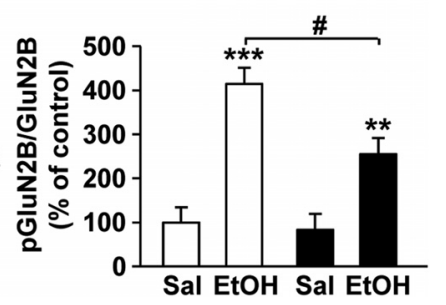

Figure 7. PTP $\alpha$ knockdown in the DMS decreases ethanol-induced Fyn activation and GluN2B phosphorylation. Mice were infused with Ltv-NS or Ltv-shPTP $\alpha$ in the DMS. Four weeks after the virus infusion, animals were treated with an acute administration of saline (Sal) or ethanol (EtOH, $2.5 \mathrm{~g} / \mathrm{kg}$, i.p.) and the DMS was collected $15 \mathrm{~min}$ later. Anti-[pY418/420] Src/Fyn and anti-Fyn antibodies $(\boldsymbol{A})$ and anti-[pY1472] GluN2B and anti-GluN2B antibodies $(\boldsymbol{B})$ were used to detect the activated form and the total amount of Fyn $(\boldsymbol{A})$ and the phosphorylated and total amount of GluN2B $(\boldsymbol{B})$, respectively. Optical density of immunoreactivity of phosphorylated-protein bands was normalized to total protein and plotted as percentage of Ltv-NS/saline treatment. $\boldsymbol{A},{ }^{* * *} p<0.001$ versus Ltv-NS/Sal. \#\#p $<0.01$ versus Ltv-NS/EtOH. $B_{,}{ }^{* *} p<0.01$, versus Ltv-NS/Sal. ${ }^{* * *} p<0.001$ versus Ltv-NS/Sal. $\# p<0.05$ versus Ltv-NS/ $\mathrm{EtOH} . n=8$ or 9 for each group.

were determined using antibodies that recognize the active form of the kinase. As shown in Figure $7 A$, and consistent with our previous finding (Wang et al., 2007), acute administration of ethanol increased Fyn activation in the DMS of mice infected with Ltv-NS (Fig. 7A); two-way ANOVA showed a significant main effect of Ltv-shPTP $\alpha$ infusion $\left(F_{(1,30)}=6.00, p=0.02\right)$, a significant effect of ethanol treatment $\left(F_{(1,30)}=8.83, p=0.006\right)$, and a significant interaction between Ltv-shPTP $\alpha$ infusion $\times$ ethanol treatment $\left(F_{(1,30)}=6.9, p=0.01\right)$ (post hoc SNK test, $q=$ $5.60, p<0.001)$. Importantly, the increase in the activity of the kinase in response to ethanol was abolished in the DMS of mice infected with Ltv-shPTP $\alpha$ (Fig. 7A; SNK test, $q=4.97, p=$ 0.002 ). As the consequence of activation of Fyn by acute ethanol administration is the phosphorylation of GluN2B (Wang et al., 2007), we tested whether PTP $\alpha$ knockdown in the DMS attenuates the phosphorylation of the subunit. As previously reported (Wang et al., 2007), we found that GluN2B phosphorylation is induced by acute administration of ethanol in the DMS of mice infected with Ltv-NS (Fig. 7B); two-way ANOVA showed a significant main effect of Ltv-shPTP $\alpha$ infusion $\left(F_{(1,29)}=5.98, p=\right.$ $0.02)$, a significant effect of ethanol treatment $\left(F_{(1,29)}=45.55\right.$, $p<0.001)$, and a significant interaction between Ltv-shPTP $\alpha$ infusion $\times$ ethanol treatment $\left(F_{(1,29)}=3.9, p=0.049\right.$ ) (post hoc SNK test, $q=8.86, p<0.001)$. However, ethanol-mediated GluN2B phosphorylation in the DMS was significantly reduced in mice infected with Ltv-shPTP $\alpha$ compared with mice infected in the DMS with the control virus (Fig. $7 B$; SNK test, $q=4.36$, $p=0.005)$. Together, these results suggest that the ethanolmediated activation of Fyn and the consequent phosphorylation of the channel subunit are controlled, at least in part, by PTP $\alpha$.

Downregulation of PTP $\alpha$ in the DMS of mice abolishes ethanol-induced long-term facilitation of NMDAR-mediated EPSCs

We previously found that acute exposure to and withdrawal from ethanol result in LTF of NMDAR activity in the DMS in a mechanism that depends on Fyn and GluN2B (Wang et al., 2007, 2010, 2011). Thus, we tested whether downregulation of PTP $\alpha$ levels in the DMS alters acute ethanol withdrawal-induced LTF of NMDAR activity. To do so, mice were infused with Ltv-shPTP $\alpha$ or Ltv-NS in the DMS, striatal slices were prepared 4 weeks later, and NMDAR-mediated EPSCs were measured in the DMS from EGFP-expressing fluorescent neurons (Fig. 8A-C). After establishing a stable recording of NMDAR-mediated EPSCs for 10 min, ethanol (50 $\mathrm{mm}$ ) was bath applied for $15 \mathrm{~min}$, ethanol was then washed out (acute withdrawal), and EPSCs were continuously measured. As shown in Figure 8D-F, PTP $\alpha$ knockdown in the DMS produced a robust modulation of the ethanol-mediated alteration of NMDAR-EPSCs (two-way RM-ANOVA), a significant main effect of Ltv-shPTP $\alpha$ infusion $\left(F_{(1,34)}=11.38, p=\right.$ $0.004)$, a significant effect of ethanol treatment $\left(F_{(2,34)}=39.46\right.$, $p<0.001)$, and significant interaction between Ltv-shPTP $\alpha$ infusion $\times$ ethanol treatment $\left(F_{(2,34)}=3.77, p=0.033\right)$. Importantly, post hoc SNK tests revealed that $\mathrm{PTP} \alpha$ knockdown cause a significant decrease in ethanol withdrawal-mediated LTF of NMDAR-EPSCs (Fig. $8 F$, post-EtOH, $q=5.48, p<0.001$ ). PTP $\alpha$ knockdown also lead to an increase in ethanol exposuremediated inhibition of NMDAR-EPSCs (Fig. $8 F, \mathrm{EtOH}, q=2.81$, $p=0.052$ ).

To confirm that the inhibition of ethanol-mediated LTF of NMDAR activity upon PTP $\alpha$ knockdown is not the result of an alteration in the basal level of NMDAR activity, mice were infused with Ltv-shPTP $\alpha$ or Ltv-NS in the DMS, and NMDAREPSCs were measured as above. After recording a stable baseline of EPSCs, the GluN2B antagonist Ro 25-6981 was bath applied, and EPSCs of NMDAR activity were continuously measured. As shown in Figure 8G, H, we found that Ro 25-6981 incubation produced similar inhibition of NMDAR-mediated EPSCs in DMS neurons of both Ltv-shPTP $\alpha$ and Ltv-NS-infected mice (Fig. $8 H ; t_{(20)}=0.50, p>0.05$ ). This result indicates that downregulation of PTP $\alpha$ does not alter the contribution of GluN2Bcontaining NMDARs to the overall activity of the channel in an ethanol-free condition.

Finally, we confirmed that the inhibition of LTF of NMDAR activity in response to $\mathrm{PTP} \alpha$ knockdown was not the result of alterations in the intrinsic features of DMS neurons. As shown in Figure 9, we found that downregulation of PTP $\alpha$ in the DMS did not alter resting membrane potential (Fig. $9 A ; t_{(17)}=0.13, p>$ 0.05 ), current-voltage relationship (Figs. $9 B, C ; F_{(1,476)}=0.26$, $p>0.05$ ), rheobase currents (Fig. $9 D ; t_{(14)}=0.63, p>0.05$ ), or excitability (Fig. 9E; $F_{(1,36)}=0.004, p>0.05$ ) of DMS neurons. These results show that PTP $\alpha$ in the DMS is required for ethanolinduced LTF of NMDAR activity.

\section{Discussion}

Here, we present data to suggest that $\mathrm{PTP} \alpha$ is a critical contributor to ethanol's actions in the DMS, and raises the possibility that the phosphatase drives and maintains the maladaptive synaptic alterations leading to uncontrolled excessive ethanol intake. Specifically, we demonstrate that silencing of PTP $\alpha$ in the DMS attenuates the activation of the Fyn/GluN2B pathway and reduces ethanol intake in rats and mice.

The DMS plays an important role in locomotion (Grillner et al., 2005) as well as goal-directed behaviors (Yin et al., 2005a, b; 

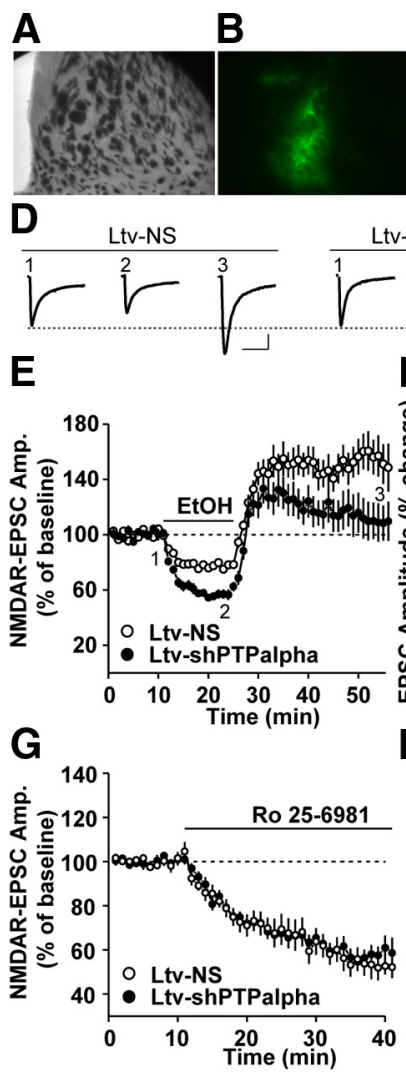

C

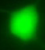

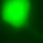
tv-shPTPalpha
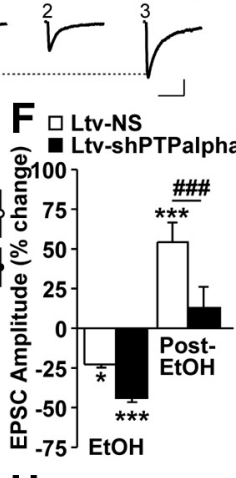

H aLtv-NS 60 Ltv-shPTPalpha

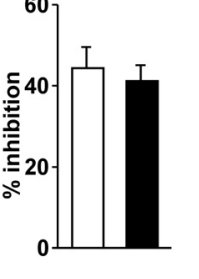

Figure 8. Downregulation of PTP $\alpha$ in the DMS increases ethanol-mediated inhibition and decreases ethanol withdrawal-induced LTF of NMDAR activity. Mice were infused with Ltv-NS or Ltv-shPTP $\alpha$ in the DMS. DMS slices were prepared 4 weeks after infusion. $A-C$, Imaging striatal infected neurons. $A$, A sample image of a coronal striatal slice. $\boldsymbol{B}$, An image showing the fluorescence of the infected area in $\boldsymbol{A}$. $\boldsymbol{C}$, Representative image of an infected neuron that was selected for whole-cell recording. $\boldsymbol{D}-\boldsymbol{F}$, NMDAR-mediated EPSCs were measured in fluorescent neurons in response to bath application of $50 \mathrm{~mm}$ ethanol. $D$, Sample traces of EPSCs from Ltv-NS (left)- and Ltv-shPTP $\alpha$ (right)-infused mice at time periods 1-3 that are indicated in $\boldsymbol{E}$. The stimulus artifacts have been omitted for clarity. Calibration: $200 \mathrm{~ms}, 60 \mathrm{pA}$. $\boldsymbol{E}$, Time course of NMDAR-mediated EPSCS before, during ( $15 \mathrm{~min}$, as indicated by the horizontal bar), and after ethanol treatment in Ltv-NS- and Ltv-shPTP $\alpha$-infected neurons. $\boldsymbol{F}$, Bar graph comparing the ethanol (EtOH) and washout (post-EtOH) effects on EPSCs. EPSCs were averaged from 10 to 15 min after ethanol application (EtOH) and from 20 to 30 min after ethanol washout (post-EtOH). $\boldsymbol{G}, \boldsymbol{H}$, inhibition of ethanol-mediated LTF of NMDAR activity is not the result of an alteration in the basal level of NMDAR activity in response to PTP $\alpha$ knockdown. $G$, Time course of NMDARmediated EPSCS before and during bath application of Ro 25-6981 (0.5 $\mu \mathrm{M})$. $\boldsymbol{H}$, Summary of the mean inhibition magnitude of NMDAR-EPSCs by Ro 25-6981 in Ltv-NS- and Ltv-shPTP $\alpha$ infected neurons in the DMS. $\boldsymbol{E}, \boldsymbol{F}$, Two-way RM-ANOVA with SNK posthoc test. ${ }^{*} p<0.05$ versus baseline, ${ }^{* * *} p<0.001$ versus baseline, \#\#\#p $<0.001 \mathrm{Ltv}$-NS versus Ltv-shPTP $\alpha . E, F, n=10$ (Ltv-NS) and 9 (Ltv-shPTP $\alpha$ ). $\mathbf{G}, \boldsymbol{H}, n=9$ (Ltv-NS) and 13 (Ltv-shPTP $\alpha$ ).

Corbit and Janak, 2010). We show that knockdown of PTP $\alpha$ in the DMS did not alter sensitivity to the hypnotic effects of ethanol, locomotor coordination in the presence or absence of ethanol, or spontaneous locomotor activity. Thus, PTP $\alpha$ in the DMS is likely to play a specific role in the mechanisms that underlie goal-directed behavior (e.g., ethanol seeking) and not locomotion. These results are consistent with recent findings that PTP $\alpha$ knock-out mice do not exhibit an abnormality in general sensorimotor capability or alterations of spontaneous locomotor activity (Takahashi et al., 2011).

The dorsal striatum was shown to play a role in the reinforcing properties of cocaine (Vanderschuren et al., 2005), and here we identified a signaling pathway in the DMS that contributes to the reinforcing properties of ethanol. Previously we provided data to

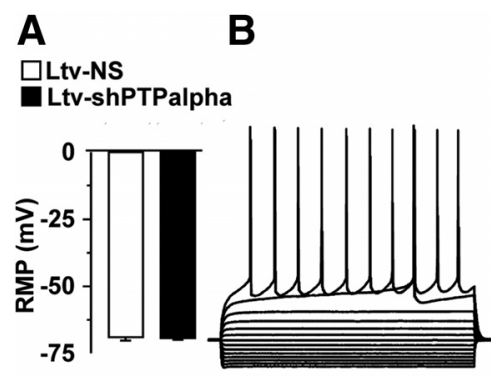

C

OLtv-NS • Ltv-shPTPalpha
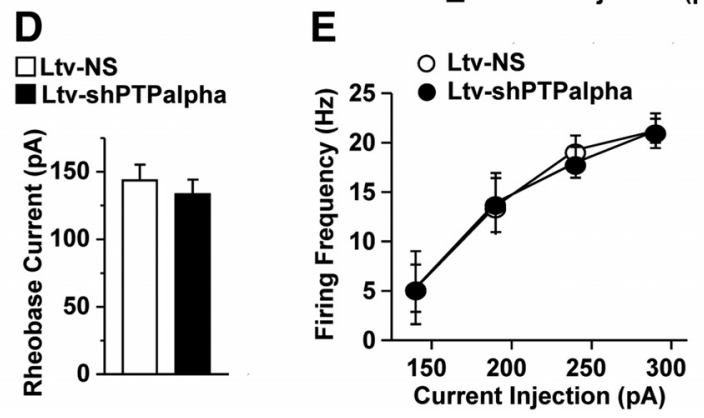

Figure 9. Downregulation of PTP $\alpha$ does not alter intrinsic features of MSNs in the DMS. Mice were infused with Ltv-NS or Ltv-shPTP $\alpha$ in the DMS, striatal slices were prepared 4 weeks after infusion, and whole-cell current-clamp recordings were conducted in fluorescent neurons. $A$, Bar graph showing no significant differences in resting membrane potentials (RMP) between Ltv-NS- and Ltv-shPTP $\alpha$-infected neurons. $\boldsymbol{B}$, Representative traces of membrane potentials in response to a series of $1 \mathrm{~s}$ current injections in a Ltv-shPTP $\alpha$-infected neuron. The injected currents were increased from -210 to $180 \mathrm{pA}$, in increments of $30 \mathrm{pA}$. C, Current-voltage (I-V) curves were plotted with membrane potentials in response to a series of current injections from -210 to $210 \mathrm{pA}$, in increments of $15 \mathrm{pA}$. The membrane potentials were measured during the last $100 \mathrm{~ms}$ of the current injection. No significant difference in the I-V relationship between Ltv-NS- and Ltv-shPTP $\alpha$-infected neurons was observed. $\boldsymbol{D}$, Bar graph comparing the rheobase currents of Ltv-NS- and Ltv-shPTP $\alpha$-infected neurons. $\boldsymbol{E}$, Excitability of Ltv-NS- and Ltv$\operatorname{shPTP} \alpha$-infected neurons. Neurons were injected with 140, 190, 240, and 290 pA currents, and the firing frequency was measured. $\boldsymbol{A}-\boldsymbol{C}, n=7$ (Ltv-NS) and 12 (Ltv-shPTP $\alpha$ ). $\boldsymbol{D}, \boldsymbol{E}, n=7$ (Ltv-NS) and 9 (Ltv-shPTP $\alpha$ ).

suggest that the Fyn-mediated signaling pathway in the dorsal striatum (Wang et al., 2007) and more specifically in the DMS (Wang et al., 2010) is an important component of mechanisms underlying the motivation of rats to seek ethanol. Specifically, we showed that intra-DMS infusion of PP2, a selective Src family tyrosine kinase inhibitor, reduced operant responding for ethanol as well as relapse to ethanol self-administration (Wang et al., $2007,2010)$. On the other hand, here, we used the home-cage ethanol intake procedure and found that manipulation of the same pathway affects ethanol drinking in the absence of an operant task that requires a certain degree of motivation. We found that $\operatorname{PTP} \alpha$, the phosphatase that dephosphorylates Fyn, in the DMS, is associated with the reinforcing properties of ethanol (e.g., voluntary ethanol intake). However, since ethanol seeking cannot be definitely tested using home-cage ethanol intake procedure, we cannot conclude from this study that PTP $\alpha$ in the DMS also contributes to the motivational process that drives the initiation of ethanol intake.

Interestingly, PTP $\alpha$ 's actions in the DMS are specific for ethanol and not generalized to natural reward or palatability. This finding is not entirely surprising given that inhibition of the downstream targets of PTP $\alpha$ (e.g., Fyn and GluN2B) in the DMS do not affect the motivation to seek and consume a naturally rewarding substance, sucrose (Wang et al., 2007, 2010). Furthermore, other signaling pathways, such as the H-Ras/mammalian target of rapamycin in complex 1 (mTORC1) in the NAc (Neasta 


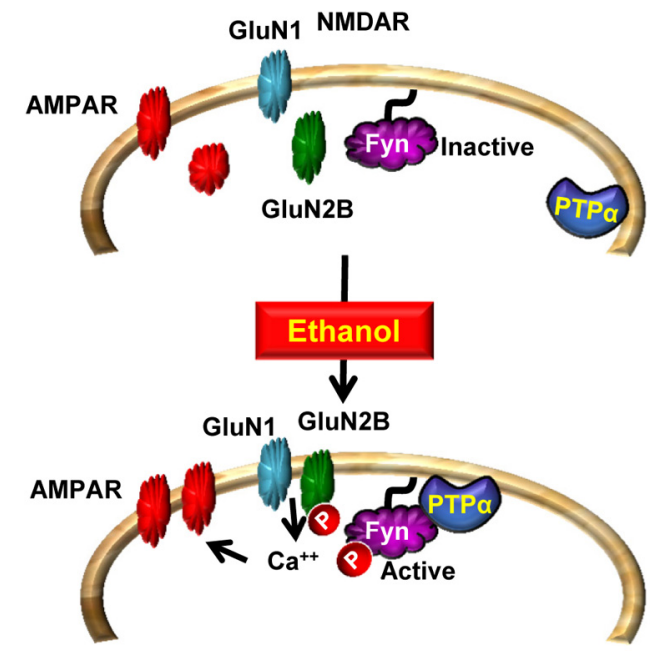

DMS

Figure 10. PTP $\alpha$ in the DMS of rodents promotes ethanol excessive drinking via Fyn. At resting state, PTP $\alpha$ is localized away from Fyn. Upon exposure of DMS neurons to ethanol, PTP $\alpha$ moves to the synaptosomal fraction where Fyn resides (Gibb et al., 2011; and herein). PTP $\alpha$ dephosphorylates the inhibitory site on Fyn, resulting in kinase activation. Fyn in turn phosphorylates GluN2B, leading to an increase in the synaptic membranal localization and activity of the channel (Wang et al., 2007, 2010, 2011). The sustained activation of NMDAR (Wang et al., $2007,2010,2011)$ leads to the movement of AMPARs to the synaptic membrane and to the enhancement of LTP (Wang et al., 2012). These plasticity events in the DMS promote excessive drinking of ethanol.

et al., 2010; Ben Hamida et al., 2012), specifically contribute to the development and/or maintenance of ethanol but, not sucrose, intake. It would, however, be of interest to determine whether PTP $\alpha$ in the DMS also contributes to mechanisms that underlie seeking of other drugs of abuse. In line with this possibility is a recent study reporting an increase in locomotor activity after acute methamphetamine administration in PTP $\alpha$ knockout mice, suggesting a possible link to the dopaminergic system (Takahashi et al., 2011; but see also Skelton et al., 2003).

Acute exposure of neurons to ethanol, including those within the DMS, results in a rapid inhibition of NMDAR activity (Yin et al., 2007; Wang et al., 2010). In a previous study, we did not observe differences in the acute inhibitory actions of ethanol NMDAR function in dorsal striatal slices from Fyn knock-out and Fyn wild-type mice (Wang et al., 2007), whereas here we show that downregulation of $\operatorname{PTP} \alpha$ increased the ethanolinduced inhibition of NMDAR activity. Thus, it is likely that PTP $\alpha$ in the DMS counteracts the rapid inhibitory effects of ethanol on NMDAR activity. Precise comparison between the two studies is difficult as previous experiments used slices from global knock-out transgenic mice in which the kinase was deleted throughout development, whereas here we temporarily reduced the level of the phosphatase specifically in the DMS. However, we cannot rule out the possibility that part of the effect of PTP $\alpha$ knockdown is mediated by a different, Fyn-independent mechanism. The heterogeneity of dorsal striatum neurons (e.g., dopamine D1 vs D2 neurons) (Gerfen and Surmeier, 2011) is another plausible explanation to the differences between the potential roles of PTP $\alpha$ and Fyn on the acute inhibitory actions of ethanol on the NMDAR activity. Specifically, it is possible that one enzyme plays a more significant role in one type of dorsal striatum neurons versus the other and that such differences are reflected in the degree of inhibitory action of ethanol on channel function.

Withdrawal from acute ex vivo ethanol exposure leads to LTF of NMDAR activity in the dorsal striatum in a mechanism that depends on Fyn (Wang et al., 2010), and here we show that downregulation of $\operatorname{PTP} \alpha$ attenuates the acute ethanol withdrawalmediated LTF of NMDAR function. These results point out the critical role of $\operatorname{PTP} \alpha$ as an upstream regulator of the Fyn and GluN2B signaling pathway, which in turn leads to the initiation of NMDAR-dependent plasticity events, such as the LTF of NMDAR activity, and to excessive ethanol consumption.

PTP $\alpha$ downregulation in the DMS did not affect the contribution of GluN2B to overall NMDAR channel activity under basal conditions and did not alter the intrinsic features of DMS neurons, including neuronal excitability. The latter finding is somewhat unexpected, given that $\mathrm{PTP} \alpha$ positively regulates the Kv1.2 potassium current in HEK293 cells (Tsai et al., 1999) and the Kv1.2 channel in the striatum negatively regulates neuronal excitability (Shen et al., 2004). However, our results are in line with Petrone et al. (2003), who reported that PTP $\alpha$ knock-out mice do not exhibit deficits in basal synaptic transmission in hippocampal slices. Therefore, under certain conditions, such as ethanol exposure, PTP $\alpha$ is recruited to activate Fyn/GluN2B signaling, leading to facilitated NMDAR activity and excessive ethanol consumption.

Putting together the results presented here with previous studies (Wang et al., 2007, 2010, 2011, 2012), we propose a model (Fig. 10) in which exposure of DMS neurons to ethanol leads to the localization of PTP $\alpha$ to synaptic membranes, the compartment where Fyn resides, resulting in the activation of Fyn, which in turn phosphorylates GluN2B. PTP $\alpha$ and Fyn-dependent activation of NMDARs in response to ethanol contributes to AMPAR that drive and maintain excessive ethanol intake. The finding that PTP $\alpha$ is a new target of ethanol raises the possibility that inhibitors of this phosphatase, which are currently in development (He et al., 2013), may represent a new direction in the discovery of novel therapeutics to treat or prevent alcohol use disorders.

\section{References}

Ben Hamida S, Neasta J, Lasek AW, Kharazia V, Zou M, Carnicella S, Janak PH, Ron D (2012) The small G protein H-Ras in the mesolimbic system is a molecular gateway to alcohol-seeking and excessive drinking behaviors. J Neurosci 32:15849-15858. CrossRef Medline

Bhandari V, Lim KL, Pallen CJ (1998) Physical and functional interactions between receptor-like protein-tyrosine phosphatase $\alpha$ and p59fyn. J Biol Chem 273:8691-8698. CrossRef Medline

Bodrikov V, Leshchyns'ka I, Sytnyk V, Overvoorde J, den Hertog J, Schachner M (2005) RPTP $\alpha$ is essential for NCAM-mediated p59fyn activation and neurite elongation. J Cell Biol 168:127-139. CrossRef Medline

Carnicella S, Amamoto R, Ron D (2009) Excessive alcohol consumption is blocked by glial cell line-derived neurotrophic factor. Alcohol 43:35-43. CrossRef Medline

Chen M, Chen SC, Pallen CJ (2006) Integrin-induced tyrosine phosphorylation of protein-tyrosine phosphatase- $\alpha$ is required for cytoskeletal reorganization and cell migration. J Biol Chem 281:11972-11980. CrossRef Medline

Corbit LH, Janak PH (2010) Posterior dorsomedial striatum is critical for both selective instrumental and Pavlovian reward learning. Eur J Neurosci 31:1312-1321. CrossRef Medline

den Hertog J, Tracy S, Hunter T (1994) Phosphorylation of receptor protein-tyrosine phosphatase $\alpha$ on Tyr789, a binding site for the SH3SH2-SH3 adaptor protein GRB-2 in vivo. EMBO J 13:3020-3032. Medline

Gerfen CR, Surmeier DJ (2011) Modulation of striatal projection systems by dopamine. Annu Rev Neurosci 34:441-466. CrossRef Medline

Gertler TS, Chan CS, Surmeier DJ (2008) Dichotomous anatomical properties of adult striatal medium spiny neurons. J Neurosci 28:1081410824. CrossRef Medline

Gibb SL, Hamida SB, Lanfranco MF, Ron D (2011) Ethanol-induced in- 
crease in Fyn kinase activity in the dorsomedial striatum is associated with subcellular redistribution of protein tyrosine phosphatase $\alpha$. J Neurochem 119:879-889. CrossRef Medline

Grillner S, Hellgren J, Ménard A, Saitoh K, Wikström MA (2005) Mechanisms for selection of basic motor programs: roles for the striatum and pallidum. Trends Neurosci 28:364-370. CrossRef Medline

He R, Zeng LF, He Y, Zhang S, Zhang ZY (2013) Small molecule tools for functional interrogation of protein tyrosine phosphatases. FEBS J 280: 731-750. CrossRef Medline

Hendriks WJ, Elson A, Harroch S, Pulido R, Stoker A, den Hertog J (2013) Protein tyrosine phosphatases in health and disease. FEBS J 280:708-730. CrossRef Medline

Jeanblanc J, He DY, Carnicella S, Kharazia V, Janak PH, Ron D (2009) Endogenous BDNF in the dorsolateral striatum gates alcohol drinking. J Neurosci 29:13494-13502. CrossRef Medline

Le HT, Maksumova L, Wang J, Pallen CJ (2006) Reduced NMDA receptor tyrosine phosphorylation in PTP $\alpha$-deficient mouse synaptosomes is accompanied by inhibition of four src family kinases and Pyk2: an upstream role for PTP $\alpha$ in NMDA receptor regulation. J Neurochem 98:1798-1809. CrossRef Medline

Lei G, Xue S, Chéry N, Liu Q, Xu J, Kwan CL, Fu YP, Lu YM, Liu M, Harder KW, Yu XM (2002) Gain control of N-methyl-D-aspartate receptor activity by receptor-like protein tyrosine phosphatase $\alpha$. EMBO J 21:29772989. CrossRef Medline

Neasta J, Ben Hamida S, Yowell Q, Carnicella S, Ron D (2010) Role for mammalian target of rapamycin complex 1 signaling in neuroadaptations underlying alcohol-related disorders. Proc Natl Acad Sci U S A 107:20093-20098. CrossRef Medline

Ohnishi H, Murata Y, Okazawa H, Matozaki T (2011) Src family kinases: modulators of neurotransmitter receptor function and behavior. Trends Neurosci 34:629-637. CrossRef Medline

Petrone A, Battaglia F, Wang C, Dusa A, Su J, Zagzag D, Bianchi R, CasacciaBonnefil P, Arancio O, Sap J (2003) Receptor protein tyrosine phosphatase $\alpha$ is essential for hippocampal neuronal migration and long-term potentiation. EMBO J 22:4121-4131. CrossRef Medline

Ponniah S, Wang DZ, Lim KL, Pallen CJ (1999) Targeted disruption of the tyrosine phosphatase PTP $\alpha$ leads to constitutive downregulation of the kinases Src and Fyn. Curr Biol 9:535-538. CrossRef Medline

Sahin M, Dowling JJ, Hockfield S (1995) Seven protein tyrosine phosphatases are differentially expressed in the developing rat brain. J Comp Neurol 351:617-631. CrossRef Medline

Salter MW, Kalia LV (2004) Src kinases: a hub for NMDA receptor regulation. Nat Rev Neurosci 5:317-328. CrossRef Medline

Sap J, D’Eustachio P, Givol D, Schlessinger J (1990) Cloning and expression of a widely expressed receptor tyrosine phosphatase. Proc Natl Acad Sci U S A 87:6112-6116. CrossRef Medline

Shen W, Hernandez-Lopez S, Tkatch T, Held JE, Surmeier DJ (2004) Kv1.2containing $\mathrm{K}^{+}$channels regulate subthreshold excitability of striatal medium spiny neurons. J Neurophysiol 91:1337-1349. CrossRef Medline

Skelton MR, Ponniah S, Wang DZ, Doetschman T, Vorhees CV, Pallen CJ (2003) Protein tyrosine phosphatase $\alpha$ (PTP $\alpha$ ) knockout mice show deficits in Morris water maze learning, decreased locomotor activity, and decreases in anxiety. Brain Res 984:1-10. CrossRef Medline

Su J, Muranjan M, Sap J (1999) Receptor protein tyrosine phosphatase $\alpha$ activates Src-family kinases and controls integrin-mediated responses in fibroblasts. Curr Biol 9:505-511. CrossRef Medline

Takahashi N, Nielsen KS, Aleksic B, Petersen S, Ikeda M, Kushima I, Vacaresse N, Ujike H, Iwata N, Dubreuil V, Mirza N, Sakurai T, Ozaki N, Buxbaum JD, Sap J (2011) Loss of function studies in mice and genetic association link receptor protein tyrosine phosphatase $\alpha$ to schizophrenia. Biol Psychiatry 70:626-635. CrossRef Medline

Tonks NK (2006) Protein tyrosine phosphatases: from genes, to function, to disease. Nat Rev Mol Cell Biol 7:833-846. CrossRef Medline

Tsai W, Morielli AD, Cachero TG, Peralta EG (1999) Receptor protein tyrosine phosphatase $\alpha$ participates in the $\mathrm{m} 1$ muscarinic acetylcholine receptor-dependent regulation of Kv1.2 channel activity. EMBO J 18: 109-118. CrossRef Medline

Vacaresse N, Møller B, Danielsen EM, Okada M, Sap J (2008) Activation of c-Src and Fyn kinases by protein-tyrosine phosphatase RPTP $\alpha$ is substrate-specific and compatible with lipid raft localization. J Biol Chem 283:35815-35824. CrossRef Medline

Vacaru AM, den Hertog J (2010) Serine dephosphorylation of receptor protein tyrosine phosphatase $\alpha$ in mitosis induces Src binding and activation. Mol Cell Biol 30:2850-2861. CrossRef Medline

Vanderschuren LJ, Di Ciano P, Everitt BJ (2005) Involvement of the dorsal striatum in cue-controlled cocaine seeking. J Neurosci 25:8665-8670. CrossRef Medline

Wang J, Carnicella S, Phamluong K, Jeanblanc J, Ronesi JA, Chaudhri N, Janak PH, Lovinger DM, Ron D (2007) Ethanol induces long-term facilitation of NR2B-NMDA receptor activity in the dorsal striatum: implications for alcohol drinking behavior. J Neurosci 27:3593-3602. CrossRef Medline

Wang J, Lanfranco MF, Gibb SL, Yowell QV, Carnicella S, Ron D (2010) Long-lasting adaptations of the NR2B-containing NMDA receptors in the dorsomedial striatum play a crucial role in alcohol consumption and relapse. J Neurosci 30:10187-10198. CrossRef Medline

Wang J, Lanfranco MF, Gibb SL, Ron D (2011) Ethanol-mediated longlasting adaptations of the NR2B-containing NMDA receptors in the dorsomedial striatum. Channels (Austin) 5:205-209. CrossRef Medline

Wang J, Ben Hamida S, Darcq E, Zhu W, Gibb SL, Lanfranco MF, Carnicella S, Ron D (2012) Ethanol-mediated facilitation of AMPA receptor function in the dorsomedial striatum: implications for alcohol drinking behavior. J Neurosci 32:15124-15132. CrossRef Medline

Yaka R, Thornton C, Vagts AJ, Phamluong K, Bonci A, Ron D (2002) NMDA receptor function is regulated by the inhibitory scaffolding protein, RACK1. Proc Natl Acad Sci U S A 99:5710-5715. CrossRef Medline

Ye H, Tan YL, Ponniah S, Takeda Y, Wang SQ, Schachner M, Watanabe K, Pallen CJ, Xiao ZC (2008) Neural recognition molecules CHL1 and NB-3 regulate apical dendrite orientation in the neocortex via PTP $\alpha$. EMBO J 27:188-200. CrossRef Medline

Ye H, Zhao T, Tan YL, Liu J, Pallen CJ, Xiao ZC (2011) Receptor-like protein-tyrosine phosphatase $\alpha$ enhances cell surface expression of neural adhesion molecule NB-3. J Biol Chem 286:26071-26080. CrossRef Medline

Yin HH, Knowlton BJ, Balleine BW (2005a) Blockade of NMDA receptors in the dorsomedial striatum prevents action-outcome learning in instrumental conditioning. Eur J Neurosci 22:505-512. CrossRef Medline

Yin HH, Ostlund SB, Knowlton BJ, Balleine BW (2005b) The role of the dorsomedial striatum in instrumental conditioning. Eur J Neurosci 22: 513-523. CrossRef Medline

Yin HH, Park BS, Adermark L, Lovinger DM (2007) Ethanol reverses the direction of long-term synaptic plasticity in the dorsomedial striatum. Eur J Neurosci 25:3226-3232. CrossRef Medline

Zheng XM, Resnick RJ, Shalloway D (2000) A phosphotyrosine displacement mechanism for activation of Src by PTP $\alpha$. EMBO J 19:964-978. CrossRef Medline

Zheng X, Resnick RJ, Shalloway D (2008) Apoptosis of estrogen-receptor negative breast cancer and colon cancer cell lines by PTP $\alpha$ and src RNAi. Int J Cancer 122:1999-2007. CrossRef Medline 